\title{
METAFÍSICA E HISTORIA DE LA METAFÍSICA: CONSECUENCIAS DE UN OLVIDO*
}

\section{METAPHYSICS AND HISTORY OF METAPHYSICS: CONSEQUENCES OF A FORGETTING}

\author{
ANTONI BORDOY FERNÁNDEZ \\ Universidad de les Illes Balears
}

\section{RESUMEN}

El presente estudio tiene como objeto el análisis de la relevancia del uso del método histórico en el ámbito de la metafísica. Para ilustrar esta relevancia, la cuestión se centra sobre la atribución a la Metafísica de Aristóteles de una definición de la ontología basada en el estudio del ser. La tesis que se pretende argumentar es que dicha atribución tiene su origen en la aproximación parcial de la historia de la metafísica y el hecho de no tomar en consideración el desarrollo paralelo de dos tradiciones que se encuentran en el siglo XIII: el pensamiento islámico, desarrollado en gran medida a partir de las obras de Aristóteles; y la tradición latina, en la que la ausencia de estas obras fue sustituida por la distinción de Boecio entre el ser y la entidad. El estudio se divide en cinco partes: planteamiento de la cuestión; interpretaciones y sesgos en la lectura de la Metafísica; transmisión de los escritos de Aristóteles y consecuencias para su interpretación;

\footnotetext{
* Financiado por: FEDER/Ministerio de Ciencia, Innovación y Universidades - Agencia Estatal de Investigación/ Proyecto: "Estudios sobre Platón y las religiones mistéricas", con la referencia FFI2017-88429-P.
} 
creación de una tradición latina y sus consecuencias; y una conclusión sobre la importancia de la historia para la metafísica.

Palabras clave: Metafísica, Ontología, Aristóteles, Boecio, Filosofía Contemporánea, Filosofía Griega, Filosofía Medieval, Historia.

\section{ABSTRACT}

This study aims to analyze the relevance of the use of the historical method in the field of metaphysics. To illustrate this relevance, the question will be focused on the attribution to Aristotle's Metaphysics of a definition of ontology based on the study of being. The thesis to be argued is that this attribution has its origin in the partial approximation of the history of metaphysics and the fact of not taking into consideration the parallel development of two traditions found in the thirteenth century: Islamic thought, developed largely from Aristotle's works; and the Latin tradition, in which the absence of these works was replaced by Boethius' distinction between being and entity. The study is divided into five parts: statement of the issue; interpretations and biases in the reading of Metaphysics; transmission of Aristotle's writings and consequences for their interpretation; creation of a Latin tradition and its consequences; and a conclusion about the importance of history for metaphysics.

Keywords: Metaphysics, Ontology, Aristotle, Boethius, Contemporary Philosophy, Greek philosophy, Medieval Philosophy, History.

\section{INTRODUCCIÓN}

En el año 1875, P. de Azcárate publicaba la versión en castellano de la $\mathrm{Me-}$ tafísica, obra con la que culminaba la traducción en diez volúmenes de los escritos de Aristóteles ${ }^{1}$. En esta obra, el autor traducía una de las afirmaciones más conocidas del Estagirita, la definición que aparece en el libro $\Gamma$ (IV) de la ontología como la primera de las dos ciencias que conforman la metafísica, de un modo que más adelante resultaría habitual: "Hay una ciencia que estudia el ser y los accidentes propios del ser" 2 . No fueron pocos los que repitieron esta expresión, en base a la idea de que "el ser, en cuanto ser, es el objeto formal de la

1 Patricio Azcárate, Aristóteles. Metafísica (Madrid: Medina y Navarro, 1875)

2 Arist. Met. 1003a 18. Traducción según la versión de Azcárate, Aristóteles. 
Filosofía Primera", e incluso ha llegado a formar parte de manuales de filosofía actuales ${ }^{4}$. Esto se debe a que a la tradición occidental no le resulta, desde la Modernidad, para nada extraña la imagen que dicha traducción transmite, a saber, que podemos distinguir, sea como hecho o como noción, el 'ser' de la 'entidad', y que la metafísica se ocupa del primero por cuanto es, valga la redundancia, ontológicamente primero. En efecto, pese a que "el ser se entiende de muchas maneras, $[\ldots]$ estos diferentes sentidos se refieren a una sola cosa, a una misma naturaleza, no habiendo entre ellos sólo comunidad con de nombre"

Las traducciones y estudios más modernos han puesto de relieve que, pese que el artículo griego tó corresponde al nominativo y acusativo en género neutro, y que ôv es el participio neutro del verbo eỉuí, lo que le confiere un valor de adjetivo verbal, no es equivalente a la sustantivización del infinitivo que se da en la expresión 'el ser'. Por el contrario, se ha concedido como traducción más adecuada la expresión 'lo que es' que, siendo correcta en castellano, respeta la estructura que sigue la expresión griega tò ôv. Resulta curioso, no obstante, que esta última versión de la traducción no sea algo nuevo -se da, en efecto, en expresiones como quod est, ya presentes en autores como Boecio-, pero que sin embargo resulte más difícil de entender. Este hecho tiene su origen en que en la actualidad estamos acostumbrados a una lectura de la metafísica en general, y de la ontología en particular, a partir de una perspectiva forjada en los siglos XVIII y XIX, de la cual la mencionada traducción de P. de Azcárate es un claro ejemplo. Una perspectiva en la que los grandes autores de la época, como G.W.F. Hegel o M. Heidegger, e inclusive el propio F. Nietzsche, tuvieron presente a la vez que olvidaron una distinción: la diferencia entre la metafísica, una ciencia humana con un objeto concreto, y la historia de la metafísica, el estudio de lo que pensaron autores anteriores. Dicho de otro modo, la historia de la metafísica, que llevaba a estos autores a buscar nociones, conceptos y estructuras en sistemas filosóficos antiguos, perdió gran parte de su contenido histórico para dibujar una línea progresiva en la que el objeto y la forma en los términos en los que se expresaban era los mismos entonces y en época clásica.

3 Gustavo Bueno y Luis Martínez, Nociones de filosofia. Quinto curso (Salamanca Anaya, 1955), 10. Esta concepción se ha mantenido vigente en diversos ámbitos y ha estructurado tradicionalmente una imagen de la metafísica basada en la ontología. Vid. i. e. Annie Hayling, "El problema del ser", Revista Estudios 6 (1985): 179-189, en donde se plantea un esquema general de la metafísica partiendo de dicha concepción.

4 Por ejemplo, José Manuel Tarrío, Filosofia. $1^{\circ}$ Bachillerato (Madrid: Editex, 2019), 88. Debido por lo general a Ley de la Propiedad Intelectual, existe una tendencia a utilizar la traducción de Azcárate, Aristóteles, lo cual ha supuesto integrar los términos de metafísica como estudio del ser en tanto que ser.

5 Arist. Met. 1003a 26-27. Traducción según la versión de Azcárate, Aristóteles. 
El objetivo de este estudio es mostrar el cómo, el cuándo y el porqué se crearon las bases de llevaron a esta confusión para, con ello, poner de manifiesto que la metafísica debe ir necesariamente de la mano de una historiografía que se rija por los mismos métodos y patrones que en el resto de las ciencias. Se pretende, en este sentido, analizar cómo este olvido de una historiografía completa creó una confusión entre dos realidades, la definida por Aristóteles en el libro $\Gamma$ y la construida por Boecio en los ocho axiomas del De hebdomadibus, interpretando la ontología a partir de la síntesis que, durante el siglo XIII, hicieron los autores latinos al encontrarse frente a una tradición occidental que, por cuestiones históricas, no había tomado en consideración la Metafísica y una filosofía árabe que, por el contrario, había construido sus nociones a partir de esta obra. Con este objeto, el estudio procederá a (1) analizar la imagen creada en la época contemporánea de Aristóteles, (2) abordar algunas de las cuestiones que se suscitan de la interpretación de capítulo 1 del libro $\Gamma$, (3) tratar el significado de los axiomas de Boecio y cómo estos llegaron a confundirse conceptualmente con las doctrinas de la Metafísica.

\section{CUESTIONES SOBRE LA INTERPRETACIÓN DE ARISTÓTELES}

La Metafísica de Aristóteles es una obra que ha sido abordada desde múltiples perspectivas, tanto en lo que se refiere a las cuestiones de contenido conceptual como a la estructura y la relación entre las dos ciencias que forman la metafísica, la غ̇ंı $\theta \varepsilon \circ \lambda \circ \gamma \iota \kappa \eta ́ ~ \varepsilon \pi \iota \sigma \tau \dot{\mu \eta}$, que bien pronto se convirtió en teología. Autores como P. Aubenque, por ejemplo, han tomado como base el libro B (III) y se han centrado en la dualidad casi irreconciliable entre ambas ciencias ${ }^{6}$. Se trata, no obstante, de interpretaciones que surgen a lo largo de un siglo XX que opta por una lectura menos sistemática de Aristóteles, aceptando la problemática de los escritos que se han conservado y la dificultad de extraer de ellos las doctrinas relativas a la metafísica. Es así que, por ejemplo, autores como W. Jaeger incluso pusieron de relieve una posible evolución interna en la obra, que bien pudiera retrotraerse a períodos de su vida anteriores de los que Andrónico de Rodas habría

6 Es el caso de Pierre Aubenque, Le problème de l'être chez Aristote. Essai sur la próblematique aristotélicienne (París: Presses Universitaires de France, 1962). El libro fue traducido al castellano como El problema del ser en Aristóteles (Madrid: Taurus, 1981). Una versión sintética de dicho problema aparece en una conferencia pronunciada por Aubenque en 1959 en la Universidad Técnica de Berlín por el mismo autor, y que más adelante sería publicada bajo el título "Aristoteles und das Problem der Metaphysik”, Zeitschrift für philosophische Forschung XV/3 (1961): 117-129. 
incorporado al menos un libro en la Metafisica ${ }^{7}$. Estos autores mencionados proceden de una tradición filológica a histórica de estudios de Aristóteles que no tuvo demasiado éxito en el ámbito de la metafísica, marcada en su mayor parte por las corrientes de origen alemán.

Pocos son los que dudan, en efecto, de que las tradiciones filosóficas que se desarrollaron en el ámbito germánico durante los siglos XIX y XX son las que tuvieron más peso en el pensamiento continental, y más importancia tuvieron en el campo de la metafísica. Fueron muchos los elementos que esta tradición exportó, tanto relativos a la demarcación general de la metafísica como a las partes que la componen, a los métodos que se utilizan para su desarrollo y a los contenidos conceptuales que la conforman. Elementos entre los cuales uno de ellos adquirió especial relevancia para la historia posterior de la metafísica: la creación de una visión genérica del mundo antiguo, en especial del griego clásico, caracterizada por la homogeneización de sus contenidos y por la proximidad de estos al pensamiento contemporáneo. Tal fue la intensidad con la que estos elementos se presentaron que, ya en el siglo XXI, G. Most resumió en seis lemas la visión de Heidegger de la filosofía griega ${ }^{8}$ : 1) los griegos de Heidegger son el Evangelio pagano; 2) hablan usando un léxico de términos filosóficos primarios; 3) los "Griegos" son sólo algunos griegos; 4) los "Griegos" son los "Griegos" de Nietzsche; 5) los "Griegos" son alemanes ataviados con togas; y 6) sus "Griegos" no son los "Griegos", pero eso es lo que realmente le interesa.

En lo que a la interpretación de la historia de la metafísica producida dentro de la metafísica alemana de los siglos XIX y XX se refiere, los estudios modernos tienden a resumirlo en una misma apreciación: se trata de una historia que pierde todo sentido histórico científico, y que se convierte más bien en una exégesis que busca la adaptación conceptual. Una historización que empieza por considerar la filosofía antigua cristiana y medieval como un elemento carente de sentido o, como lo denomina Hegel, a modo de filosofemas expresos en una religión ${ }^{9}$. Más adelante, F. Van Steenberghen habría de resumir la mirada

7 Es la tesis defendida por el autor en Werner Jaeger, Grundlegung einer Geschichte seiner Entwicklung (Berlín: Weidmann, 1923). Jaeger trató, además, de reconstruir a partir de fragmentos y evidencias parte de las obras perdidas, como el Protréptico, para poner de manifiesto el carácter evolutivo del pensamiento aristotélico. De la misma época es el libro de David Ross, Aristotle (Londres: Methuen, 1923), que también supuso un revulsivo en los estudios de Aristóteles.

8 Glenn Most, "Ross", Arion: A Journal of Humanities and the Classics 10 (2002): 83-9. En la misma línea, existe un estudio anterior interesante, Rainer Marten, "Heidegger and the Greeks", en The Heidegger case: on philosophy and politics, ed. Tom Rockmore (Filadelfia: Temple University Press, 1992), 167-187.

9 Así es denominado en las Vorlesungen über die Geschichte der Philosophie, que impartió en diversas universidades: de 1805 a 1806 en Jena; de 1816 a 1818 en Heidelberg; y de 1819 a 1831 en Berlín. Lecciones que fueron transcritas y publicadas póstumamente por Karl Ludwig Michelet entre 
moderna y contemporánea de la filosofía hacia la época medieval como "una reacción más violenta que una simple condena de un antiguo pasado del que se guarda un molesto recuerdo, sino todavía la lucha actual contra el orden de las cosas que persiste y que en ocasiones se defiende con fuerza de quienes innovan: subsisten el papado y la Iglesia"10. De este modo, autores como Hegel o Heidegger se hicieron eco de un pensamiento germánico moderno y contemporáneo que buscaba en el mundo griego sus raíces y justificación, en tal medida que suprimieron de la Edad Media cualquier valor filosófico. Tan sólo en determinados casos se le dio a la Escolástica un cierto reconocimiento, basado en haber sabido precisar terminológicamente los conceptos antiguos relacionados con el ser y la esencia. Existía, pues, una correlación directa entre el pensamiento europeo contemporáneo y la filosofía griega de época clásica.

Uno de los ámbitos de la metafísica en la que mayor incidencia ha tenido esta forma de percibir la historia ha sido en la interpretación de los conceptos que estructura el objeto de estudio de la ontología: el ser, la entidad y la existencia. Grosso modo, las cuestiones que se han suscitado en este ámbito derivan de una triple desviación del sentido histórico. En primer lugar, se redujo la última parte del pensamiento metafísico tradicional, el que corresponde a la plena y baja Edad Media, a ontoteología, considerando secundario o de poca importancia todo lo que atañía a las entidades y al mundo ${ }^{11}$. En segundo lugar, el rechazo generalizado a lo medieval condujo a la homogeneización del pensamiento antiguo, creando con ello un 'modo griego' o un 'pensar griego' que correspondería a 'los Griegos'" , dejando de esta forma de lado las diferencias internas y, máxime, trasladando una imagen intelectual a la realidad cotidiana de las culturas griegas. En tercer lugar, la exégesis del pensamiento tradicional se centró en exceso sobre conceptos y estructuras, dejando de lado realidades históricas

los años 1833 y 1836. En éstas utiliza el término 'filosofema', extraído de la lógica aristotélica, para designar la Patrística y la Escolástica como dos tradiciones que desarrollan argumentos filosóficos pero que, en realidad, no pueden ser consideradas como tales al tomar sus principios o axiomas del dogma cristiano.

10 Fernand Van Steenberghen, Introduction à l'étude de la philosophie médiévale (Lovaina / París: Publications Universitaires / Béatrice-Nauwelaerts, 1974), 36. El análisis de Van Steenberghen permite observar cómo la construcción de la historia de la filosofía medieval está excesivamente marcada por la herencia del romanticismo alemán, en base al cual pese a poder recuperarse la época como objeto de estudio se introducen en ella una serie de concepciones que transforman su significado y contenido.

11 Esta reducción no resulta extraña, por cuando el propio Martin Heidegger parte de lo que se denomina una "interpretación ontoteológica" de la Metafísica de Aristóteles, es decir, que suprime la dualidad entre ontología y teología a partir de un primado de Dios.

12 Con respecto a esta expresión, vid. i. e. Heidegger, GA 40.15; 40.17 o 40.18. Ésta es una de las expresiones que Glenn Most, "Heidegger's Greeks", critica como unificación de la multiplicidad histórica, geográfica y sociológica griega en la unidad de los filósofos de época clásica. 
consideradas menores, como la situación de la transmisión de los textos en un momento concreto, y sólo tuvo en cuenta aquéllas que, como las condenas a la filosofía o los grandes acontecimientos, provocaron. De este modo, la historia de la filosofía se convirtió en gran medida en una filosofía sin historia, que pese tener en cuenta las diferencias cronológicas y culturales no consideraba las particularidades de cada momento.

Entre los diferentes casos que podrían considerarse afectados por este proceso, uno llama en especial la atención debido a las consecuencias que tuvo: la interpretación de Metafísica 1003a 21-26, en donde Aristóteles expone los principios básicos que articulan la ontología como ciencia primera. Unas líneas que sirvieron a autores como M. Heidegger para atribuir un determinado concepto de ser al Estagirita y que después fueron trasladadas tanto sobre el resto de su pensamiento como sobre el de otros autores, en especial Parménides. La ausencia de inclusión de elementos históricos provocó, como pretende mostrarse, que la interpretación generalizada no respondiese al sentido interno del libro IV de la Metafísica, sino más bien a la concepción dada en el De Hebdomadibus de Boecio. La razón subyacente parece residir en el hecho de que el punto de referencia tomado es el pensamiento del siglo XIII, máxime las interpretaciones de índole tomista, dejando de lado que en este período se ha producido ya la confluencia entre una tradición latina en la que la Metafísica había desaparecido y había sido substituida conceptualmente por otro modelo, y la tradición árabe, que sí había recibido desde sus orígenes la mencionada obra de Aristóteles, construyendo a partir de ella un concepto distinto de ciencia primera.

\section{ORÍGENES DE LA CUESTIÓN: DE LAS CUESTIONES DE TRANSMI- SIÓN DE LA METAFÍSICA A LA INTERPRETACIÓN DEL OBJETO DE LA ONTOLOGÍA}

\section{LA EdAD Media Y El NUEVo ARISTÓteles (O EL ARISTOTELES LATINUS)}

Uno de los momentos de la historia que mejor permiten observar las consecuencias que tuvo la transmisión fragmentada corresponde al mundo latino de los siglos XII y XIII, en los que convergen un mínimo de cuatro Aristóteles ${ }^{13}$ : a) el generado a partir de la transmisión latina, en la que básicamente se conserva

13 Una de las mejores presentaciones del estado de las obras de Aristóteles en los siglos XII y XIII, así como de los traductores y lenguas a partir de las que se producen los textos, corresponde a Bernardus G. Dod, "Aristoteles latinus", en Cambridge History of Later Philosophy, ed. Norman Kretzmann, Anthony Kenny y Jan Pinborg (Cambridge, Cambridge University Press, 1982), 45-79. Aunque existen otros estudios, en la catalogación y clasificación de obras que se encuentra en el presente estudio se sigue el mencionado trabajo de Bernardus G. Dod. 
a partir de la denominada logica vetus y algunas menciones parciales que serán recogidas en compilaciones como los florilegios; b) el que se recibe gracias a las traducciones del árabe, en donde se habían conservado tanto la Metafísica como los que serán conocidos como libri naturali (escritos sobre filosofía natural), además de incorporar las paráfrasis y comentarios de autores como Avicena o Averroes; c) el espurio, heredado en su mayor parte también del mundo árabe, y que incluye desde pequeños tratados a obras como el Liber de causis, confeccionado en base a tratados de otros autores (en este caso, Plotino y Proclo); y d) el griego que, junto a otras obras, entra en Occidente gracias a una segunda translatio studiorum ${ }^{14}$, dando lugar a una nueva traducción de las obras del Estagirita $^{15}$. El resultado de ello es lo que se conoce como Aristoteles latinus, compuesto por múltiples escritos, algunos de ellos en traducciones que en la actualidad se considerarían fieles al original.

Este proceso de reconstrucción de los textos aristotélicos en una versión latina no puede considerarse sin atender a su desarrollo cronológico, pues no se trata de una serie de versiones que mejoran y se van sustituyendo entre sí. En efecto, desde principios del siglo VI y gracias a las traducciones de Boecio, el mundo latino conoce e incorpora al acervo cultural parte del organon aristotélico, la logica vetus: las Categorías, el Sobre la interpretación, los Analíticos primeros, los Tópicos y las Refutaciones sofísicas, a las que además se añade la traducción de la Isagoge de Porfirio de Tiro. A partir de ese momento será posible encontrar referencias a otras obras de Aristóteles, pero serán marginales y su desconocimiento será progresivo hasta principios del siglo XII cuando, autores como Jaime de Venecia, inician un proceso de traducción de las obras conservadas en lengua árabe. Es en ese momento cuando empiezan a aparecer otros tratados, y no sólo relativos al organon, sino también a lo que se conocerá como libri naturali -tratados sobre la naturaleza, como la Física- y metaphysica. Como se ha dicho ya, estas traducciones incluyen tanto comentarios y paráfrasis de autores islámicos como obras espurias: en el primer caso figuran comentarios como los de Averroes (divididos en breves, medios y largos), así como libros como la Teología de Aristóteles y el Liber de causis, gestados en los ambientes árabes del siglo IX y que rellenaban los aspectos que, se creía, se habían perdido de tratados como la Metafísica.

14 Son muchos los estudios que se han realizado sobre este tema, pero para una descripción sintética del proceso que siguió esta segunda translatio studiorum puede encontrarse en Francisco León, "Translatio Studiorum: Traslado de libros y diálogo de civilizaciones en la Edad Media", Revista General de Información y Documentación 15.2 (2006): 51-77.

15 Con respecto a la evolución de las obras de Aristóteles en el mundo cristiano oriental, vid. Héctor Ricardo Francisco, "La transmisión de saber aristotélico en el Cercano Oriente cristiano", El arco y la lira. Tensiones y debates 4 (2016): 85-100. 
No han sido pocos los estudios que han intentado abordar la relación causal que existió entre las traducciones de las obras de Aristóteles y los conflictos que, desde finales del siglo XII, se produjeron en el mundo latino. En efecto, es cierto que en esta época se observa una polémica en torno a las obras del Estagirita que, en las dos primeras décadas del XIII, da lugar a la exhumación del cuerpo de Almarico de Bena - con objeto de excomulgarlo- o a la prohibición y quema de los libros de David de Dinant, ambos considerados panteístas que construyen su sistema a partir de los escritos de Aristóteles y las paráfrasis árabes. También es cierto que, desde comienzos del siglo XIII, aparecen en el contexto de la universidad parisina una serie de limitaciones a la enseñanza de los libri naturali y la metaphysica aristotélicas: en 1210 y 1215, o las condenas de 1270 y 1277 , por mencionar algunos ejemplos ${ }^{16}$. No obstante, los estudios modernos no están de acuerdo sobre la sustancialidad de la problemática aristotélica: mientras que unos sugieren que se trata de una lucha contra este autor, otros abogan porque se trata de la consecuencia de una asociación con la demanda de autonomía de los maestros de artes y, en fin, otros sugieren que no hay tal oposición al aristotelismo, sino sólo una precaución necesaria dada la pluralidad y falta de revisión de los textos del Estagirita.

Sea como sea, lo cierto es que las traducciones del griego, en especial las elaboradas por Guillermo de Moerbeke, permitieron cambios sustanciales en la imagen de Aristóteles. Éstas dieron paso a una lectura mucho más directa de los textos que, entre otros, dará como consecuencia una exégesis más precisa y depurada que se transmitirá a la Modernidad. En efecto, no sólo aparecen por primera vez en siglos obras como la Política, la Retórica o la Poética, que permiten completar la tradición, sino que además es gracias a las nuevas traducciones que Tomás de Aquino pudo definitivamente resolver que el Liber de causis era en realidad una adición de fragmentos de los Elementos de teología de Proclo y de las Plotiniana arabica o compilación fragmentada de las Ennéadas IV-VI de Plotino. De todo ello resultó un Aristóteles mucho más completo y unificado,

16 En el año 1210 Pierre de Corbeil emitió la primera regulación oficial del curso escolar que, a parte de establecer los calendarios y las tipologías de cursos, limitaba el uso de las obras de Aristóteles y prohibía la lectio de los libri naturali, la Metaphysica y las paráfrasis creadas a partir de ésta, además de insistir en las condenas al difunto Amarico de Bena y a David de Dinant. La regulación de 1215, llevada a cabo por Robert de Courçon, insistía en las mismas limitaciones. La bula Parens scientiarum, de 1231, introducía la posibilidad de enseñar dichas obras, pero previamente establecía la necesidad de un comité censor. Las condenas de 1270 y 1277 han sido discutidas por su contenido y por la imposibilidad de fijar referencias exactas en muchos de los artículos que menciona. En cualquier caso, estas últimas condenan presentan una mayoría de elementos que refieren de manera más o menos explícita al pensamiento aristotélico tal y como había sido recibido a lo largo de los siglos XII y XIII. Para un análisis más extenso de estas consecuencias, vid. Antoni Bordoy, Enseñar filosofia en los albores de la Universidad (1200-1240). Estudio histórico acompañado del 'Acceso de los filósofos a las siete artes liberales' (Madrid, Sindéresis, 2019). 
pues de hecho se trataba de la primera vez en la historia que había seguido a la edición de Andrónico de Rodas, que las obras del Estagirita se sistematizaban y depuraban. No obstante, este proceso también dio lugar a una imagen del aristotelismo que habría de perdurar en Europa y que, para el caso que aquí ocupa, tuvo consecuencias relevantes.

\section{CUESTIONES SOBRE LA LECTURA UNIFICADA DE LA METAFÍSICA}

A lo largo de la historia, la mayoría de los comentaristas han analizado la Metafísica desde la perspectiva de una obra unitaria que aborda la realidad que

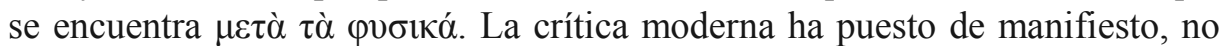
obstante, que en realidad se trata de una obra compilada a partir de diversos grupos de libros, algunos de los cuales mantienen una cierta unidad entre ellos. Dos son los grupos de elementos que avalan esta tesis: históricos y de contenido. En el primer caso, el primer hecho a tener en cuenta es que la Metafísica no fue compuesta como tal por Aristóteles, sino que corresponde a una serie de libros que Andrónico de Rodas ${ }^{17}$, director del Liceo en el siglo I aC, al realizar la edición de las obras del Estagirita los consideró en una unidad temática que no correspondía al resto de bloques. Cabe tener en cuenta, asimismo, que el trabajo de Andrónico se realizó sobre los libros que habían vuelto a Occidente en época de Lucio Cornelio Sila y de Lucio Licino Lúculo, pero que desde que la biblioteca del Liceo quedó en manos de Neleo, estos habían desaparecido y viajado a diferentes geografías. De este modo, tampoco es posible asegurar que la Metafísica contenga el conjunto de libros que hubiesen formado parte de ella o que algunos de ellos tuviesen unidad con otros. Además, al igual que sucede con el resto de las obras, los tratados que contiene corresponden a las lecciones internas del Liceo, es decir, a obras acromáticas de las que es posible que sean inclusive apuntes o libros previos a la discusión y a su corrección.

En lo que a los elementos que afectan a la unicidad del contenido, la crítica moderna ha puesto re relieve diversos hechos. El primero es que, por temática, cada libro o grupo de libros puede bien constituir un curso completo en sí mismo, que, en ciertos casos, además, parece estar relacionado con obras como la Física. Resulta pues, imposible, determinar con exactitud el contexto de referencia de los libros. El segundo hecho a tener en cuenta es la imposibilidad de definir,

17 Es necesario tener en cuenta que, a diferencia de quienes habían tratado previamente de compilar los escritos de Aristóteles, Andrónico de Rodas era director de un Liceo que había logrado mantener su tradición. Autores posteriores, como Estrabón o Plutarco, reconocen la calidad del trabajo de Andrónico en contraposición a, por ejemplo, Tiranión, quien precisamente le había hecho llegar a él los libros. 
pese a los intentos de autores como W. Jaeger, una secuencia cronológica de los $\operatorname{libros}^{18}$ : la falta de referencias externas, la redacción y las relaciones internas impiden situarlos en orden de composición, en tal medida que incluso se ha sugerido la posibilidad de que no todos los libros hayan sido compuestos en el último de sus períodos de escritura. Este último hecho afecta de manera ostensible por cuanto la Metafísica, pese a su unidad, contiene elementos que parecen entre sí contrarios o que no mantienen una correspondencia estructural, bien que debido a la compilación son abordados de forma conjunta. En el caso de la definición de una metafísica como ciencia estos elementos afectan de manera ostensible, pues precisamente una de las cuestiones tradicionales que afecta a la obra es la presentación, en el libro A (I), de la sabiduría en relación con el conocimiento de las causas y el establecimiento, en los libros $\Gamma$ (IV) y A (XII), de dos ciencias, ontología y teología, que tienen objetos diferentes y que ocupan este mismo lugar ${ }^{19}$.

\section{EL CONTEXTO DE PRESENTACIÓN DE LAS DOS CIENCIAS METAFÍSICAS}

Atendiendo a las dificultades de interpretación que ha suscitado la crítica textual moderna parece un error, en consecuencia, plantear una exégesis del significado que Aristóteles atribuye a la metafísica como ciencia partiendo de una lectura secuencial y directa de la Metafísica. En efecto, el desarrollo de una exégesis de este tipo sería tan sólo posible si se dispusiera de una obra compuesta como un todo, en donde los elementos externos e internos a los que se refiere constituyeran una unidad de referencia sustancialmente invariable. No obstante, estos hechos no implican la imposibilidad de establecer una interpretación más o menos aproximada del significado original que Aristóteles habría dado a la metafísica, sino tan sólo que deben aplicarse principios correctores. Entre estos, los estudios modernos han señalado dos requerimientos básicos: la necesidad de abordar los libros atendiendo a la estructura no unitaria de la Metafísica, es decir, a las referencias internas, los grupos de libros y las posibles relaciones externas; y la aproximación a la referencia lingüística que, en su contexto de composición, habrían tenido las diferentes afirmaciones y conceptos que plantea el Estagirita.

En el caso de la lectura ordenada de los libros, es necesario tomar en consideración dos hechos: el lugar que ocupa cada libro dentro de la Metafísica, no

18 Vid. Jaeger, Aristoteles.

19 Las tesis mencionadas de Pierre Aubenque en el punto 2. del presente estudio están orientadas, precisamente, a mostrar que se trata de una dualidad irreconciable entre las dos ciencias. Tesis opuesta a la versión ontoteológica de Martin Heidegger, pero también a la lectura teológica de autores como Hans George Gadamer. 
en la secuencia implantada por Andrónico de Rodas sino en cuanto a contenido doctrinal; y la estructura que, por referencias de contenido, plantean los diversos libros. En este contexto, cabe señalar que se acepta la existencia de diversas secuencias internas y de libros sueltos: el libro $\Gamma$ (IV), en donde se define la ontología como ciencia primera, constituye una unidad doctrinal con los libros A (I), B (III) y E (VI) que, además, enlazan con otra serie formada por los libros Z (VII), H (VIII) y $\Theta$ (IX); por su parte, el libro A (XII), en donde se plantea la teología, no se considera como parte de ninguna unidad temática, con lo que queda suelto dentro de la obra, intercalado por orden lógico en lo que sería el estudio ascendente de las realidades que están más allá de la naturaleza. Este contexto permite extraer unas primeras conclusiones: la definición de la ontología (libro $\Gamma$ ) está en relación a la búsqueda de una ciencia primera y universal (libro A) y a los problemas que, a modo de aporías, se derivan de dicha búsqueda (libro B), culminando con la necesidad intrínseca de esclarecer el significado de "ser" (libro E); el segundo grupo de libros relacionados $(\mathrm{Z}, \mathrm{H}$ y $\Theta$ ) estarían dedicados a bordar las cuestiones específicas del significado de ese ser y sus referencias; por su parte, el libro A (XII), en donde se plantea el estudio de un ente concreto, no tendría correlación con dichos libros, pero habría sido emplazado en esa parte como herencia de un problema relacionado con la explicación física que viene sintetizada por el libro K (XI). En este contexto, curiosamente, la teología parecería ser más bien una ciencia orientada a abordar un problema derivado de la causalidad del movimiento más que del ser, lo cual correlaciona de forma directa con el concepto de primer motor.

Esta estructura interna muestra, asimismo, que existe una correlación directa entre la construcción de la ciencia universal y primera y una serie de cuestiones de tipo lingüístico. En efecto, los estudios modernos han señalado que, pese a las divergencias y diferencias internas, existe un patrón común que se repite en casi todos los casos: la dependencia generalizada con respecto de los libros B (III) y $\Delta$ (V). Las tres primeras aporías del libro B (III) centran, de este modo, la cuestión: la necesidad de una ciencia universal y el problema de las múltiples causalidades de las entidades, de las cuales debe buscarse entre ellas cuál corresponde en realidad a la sabiduría (B III.1). El planteamiento de la ontología en el libro ( $\Gamma$ IV) vendrá a cubrir la forma en la que debe interpretarse esa causalidad primera de las entidades, reduciéndola al estudio de 'lo que es en tanto que es'. El libro V sigue una estructura pareja en las definiciones: principio, causa, elemento, naturaleza, necesario, uno / unidad y, al fin, 'lo de que es', en tal medida que la secuencia que siguen los capítulos centra los problemas derivados de las aporías y la definición dada de la ontología. El problema de 'lo que es', además, considera Aristóteles que tiene un origen claro: “'Lo que es' se dice 
tal ya accidentalmente ya por sí mismo" ( $\Delta$ V.7), es decir, que está sometido a múltiples acepciones que culminarán con los sentidos que analiza, tales como entidad o sujeto. Fijar el objeto de estudio supone, con ello, especificar el sentido de la expresión 'lo que es', utilizada en el lenguaje de la época-como en el resto de los lenguajes- de muy diferentes modos.

Los estudios modernos han realizado, asimismo, una serie de apreciaciones sobre la expresión $\tau$ ò ôv î̃ ôv con la que se describe el objeto de la ontología. La primera, de carácter lingüístico, es que el uso del artículo $\tau \tilde{\omega}$, en forma de nominativo dual, ha sido en ocasiones utilizado para traducir tò ồ como 'el ser', situándose en la base de interpretaciones contemporáneas que lo definen como un elemento distinto de las entidades ${ }^{20}$. No obstante, este tipo de traducciones olvida el hecho de que se trata de un participio presente neutro del verbo cíuí que, en dicha forma, es utilizado a modo de acusativo, convirtiéndose en un

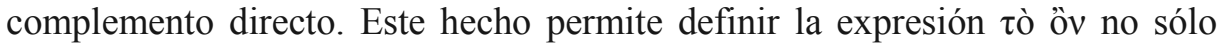
como un sustantivo, sino también a modo de indicación de propiedad de algo, confiriéndole un sentido existencial que a la vez implica presencialidad y movimiento. De este modo, tò ồv se corresponde con algo que es en este momento, es decir, algo que 'está siendo'. La ontología es, por consiguiente, el estudio lo que es en tanto que es, es decir, de las cosas que son en tanto que están siendo en una línea temporal dada. La traducción, como también se ha propuesto, por 'entidad', mantiene en cierto modo este carácter existencial, pero elimina del concepto la temporalidad por cuanto pueden existir en un momento distinto. El hecho de que en el libro A (XII) el primer motor sea tratado como una entidad refleja a la perfección esta situación, pues se trata de algo que está siendo pero que, a diferencia del resto de cosas que son, ésta perdura de una forma continua en el tiempo, lo que más adelante sería traducido como 'eterno'.

En línea con esta idea, se ha señalado también la imposibilidad de interpretar las expresiones relativas a la oủoí $\alpha$ sin tomar en consideración las explicaciones que aparecen en las Categorías"1. En primer lugar, porque "Aristóteles denomina preferencialmente $\tau o ́ \delta \varepsilon \tau \imath$, 'este algo', a lo que en el cuadro de las categorías contesta a la pregunta ‘¿qué es?"'22 Este hecho se puede observar en las diferentes expresiones que aparecen en el libro VII en relación a los

20 Sucede así, por ejemplo, en la versión de Patricio de Azcárate: "El estudio del ser en tanto que ser". Ya se han mencionado otras explicaciones que siguen esta línea, como sucede en el caso de Gustavo Bueno. Vid. n. 3 del presente estudio.

21 Es la tesis defendida por António Pedro Mesquita, "Platón y Aristóteles. Dos ontologías en confrontación", Estudios de Filosofia 53 (2016): 55-79. La tesis del autor parte del proyecto de traducción del Aristóteles en lengua portuguesa. Se basa, en este sentido, en una identificación de los contenidos de la Metafisica con las Categorías a partir de cuestiones tanto de pensamiento como lingüísticas.

22 Mesquita, "Platón y Aristóteles", 68. 
conceptos sustanciales: si bien el sujeto aparece designado como tò

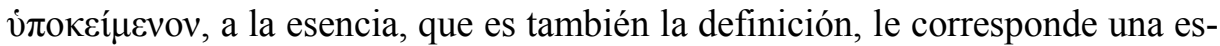

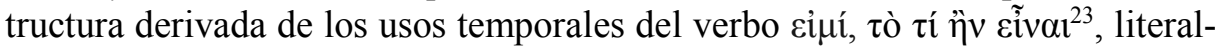
mente 'lo que es siendo'. El sentido atribuido a la esencia recalca la necesidad de, aunque es posible traducirlo por 'el ente', mantener la idea de acción en la expresión $\tau$ ò ôv. En segundo lugar, además, que las propias Categorías definen el significado que debe darse a la sustancialidad expresada con la oủ $\sigma i ́ \alpha$ y la imposibilidad de separarla de las atribuciones existenciales ${ }^{24}$ :

Pero, de todos los modos en que se dice ( $\tau$ ò ôv), resulta evidente que el primer es lo que es, el cual significa la sustancia (ov̉øía); puesto que cuando decimos

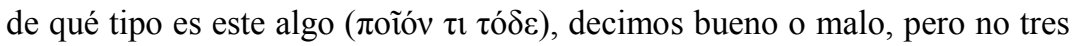
codos u hombre [...] Por tanto, resulta claro que cada uno de aquéllos es por medio de ésta, de tal modo que lo que es primeramente ( $\tau$ ò $\pi \rho \omega ́ \tau \omega \varsigma$ ồ) -no lo que es algo, sino lo que es simplemente (ồ $\dot{\alpha} \pi \lambda \tilde{\omega} \varsigma$ )-, ha de ser la sustancia.

El objetivo de la ontología, tal y como se define en Metafisica ( $Г$ IV.1), es, por consiguiente, algo determinado y de lo que existe una referencia directa. Se trata, como se sugiere a partir de las Categorías, de aquello que es algo, lo que se encuentra subyacente al resto de atribuciones y que permite que una cosa sea. En este sentido, aunque la ontología propone un análisis de lo que es primero, anterior en sentido existencial a los accidentes que determinan una sustancia, no implica la definición de un ser genérico libre de cualquier relación existencial. En cierto modo, la idea de entidad como traducción de $\tau$ ò ôv mantiene esa referencia directa a la existencia y al hecho de estar siendo, pero también suprime parcialmente la idea de movimiento que viene fijada con el participio y que, además, se encuentra en relación con el problema planteado en el libro I, a saber, la necesidad de hallar un principio universal en una naturaleza que se encuentra en movimiento.

23 En torno a esta expresión y su significación en las obras de Aristóteles, vid. Lambros Cou-

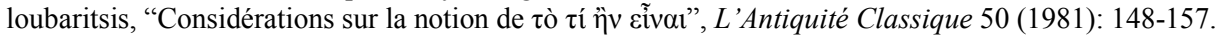

24 Ar. Cat. 1028a 13-30, según traducción de Mesquita, "Platón y Aristóteles", 60. 


\section{BOECIO Y LA NECESIDAD DE EL DE HEBDOMADIBUS: CONSE- CUENCIAS PARA LA TRADICIÓN}

1. Boecio, de la herencia de la metafísica a la sustantivización del ser

La historia ha resaltado la importancia que tuvieron las obras de Boecio en dos grandes ámbitos: la transmisión del saber antiguo al mundo latino, que no sólo se reduce a cuestiones filosóficas sino también a disciplinas como la música y las matemáticas; y por ser uno de los pilares sobre los que se asentó la latinitas cristiana, el modo de ver y entender el mundo propio de Occidente durante la Edad Media y parte de la Modernidad ${ }^{25}$. Dos ámbitos que no pueden considerarse por separado, ya que sus traducciones del griego y la compilación de obras antiguas está en relación directa con la forma y los fundamentos sobre los que su pensamiento se erige. Así, por ejemplo, las compilaciones y paráfrasis que se encuentran en la base de la Institutio Arithmetica, por ejemplo, mantienen un vínculo directo con su idea de delimitar el espacio de una sabiduría separada del ámbito de lo teológico, más tarde identificada como quadrivium, cuyos contenidos serán las cuatro matemáticas (aritmética, geometría, música y astronomía).

En lo que al ámbito de la metafísica se refiere, no obstante, la tradición que toma Boecio es distinta. Dos son los elementos que influyen. El primero, que el objetivo principal del autor no es el de, a modo de lo que había hecho con las matemáticas, generar una metafísica centrada en un ámbito distinto del de la teología. En cambio, su idea consiste en identificar el ser con Dios, en una línea semejante a lo que autores anteriores habían hecho en la imagen del summum bonum. El segundo, asimismo, es el origen doctrinal que toma: su punto de referencia con respecto al saber antiguo lo constituye el neoplatonismo de la escuela de Roma, es decir, de Plotino y Porfirio de Tiro, en donde la metafísica aristotélica había sido sustituida por la platónica tomada del Parménides y la República. De este modo, Boecio carece de la referencia directa a Aristóteles, y utiliza los conceptos relativos al ser que aparecen en las obras de los neoplatónicos de la época, en especial, las Categorías. Es así que la traducción boeciana de los tratados aristotélicos se centrará en el ámbito del organon, dando forma a la denominada logica vetus: las mencionadas Categorías, el Sobre la interpretación, los Analíticos primeros, los Tópicos y las Refutaciones sofísticas, a los que añade la traducción de la Isagoge de Porfirio, una introducción a las Categorías, y una serie de comentarios suyos como el Sobre la división, Introducción

25 Manuel Lázaro, Historia de la Filosofia Medieval y Renacentista I (Madrid: Sindéresis, 2018), 111-112. 
a los silogismos categóricos, un Comentario a los Tópicos de Cicerón y el Sobre las diferencias tópicas.

En conjunto puede verse cómo los contenidos que Boecio extrae de Aristóteles, pese a abordar cuestiones sobre la entidad, no hacen referencia a la Metafísica, sino a obras de carácter lógico que, es evidente, mantienen una relación sistemática con dicho tratado pero no su estructuración. De este modo, Boecio dará origen a lo que se considera el 'problema de los universales', a saber, si género y especie (los arquetipos) se encuentran in re, existen ante rem o son post rem. Este problema es, a su vez, heredado del propio Porfirio, quien en su Isagoge plantea la pregunta de cuál es la relación de los universales con la oủoí $\alpha$, pero sin plantear una posible interpretación. En cambio, en el De Hebdomadibus, una obra cuyo punto de referencia dista de ser la Metafísica, plantea siete axiomas sobre el ser y el ente ${ }^{26}$ :

I. Communis animi conceptio est enuntiatio, quam quisque probat auditam. Harum duplex modus est. Nam una ita communis est, ut omnium sit hominum, veluti si hanc proponas: "Si duobus aequalibus aequalia auferas, quae relinquantur aequalia esse", nullus id intellegens neget. Alia vero est doctorum tantum; quae tamen ex talibus communibus animi conceptionibus venit, ut est: "Quae incorporalia sunt, in loco non esse", et cetera, quae non vulgus sed docti comprobant.

II. Diversum est esse et id quod est; ipsum enim esse nondum est, at vero quod est, accepta essendi forma est atque consistit.

III. Quod est, participare aliquo potest, sed ipsum esse nullo modo aliquo participat. Fit enim participatio cum aliquid iam est; est autem aliquid, cum esse susceperit.
I. Una concepción común de la mente es un enunciado que cada uno aprueba una vez que lo ha oído. La clase de estos es doble. Pues uno es a tal punto común que es propio de todos los hombres, como por ejemplo si propusieras este: si de dos cosas iguales sacas cosas iguales, las cosas que quedan son iguales; nadie que lo entienda lo negaría. Pero otro es solamente propio de los sabios. Y con todo proviene de esas concepciones comunes de la mente, como es este: las cosas que son incorporales no están en un lugar, y otros que comprueban los sabios no el vulgo.

II. Son diversos el ser y lo que es. Por cierto, el ser aún no existe, en cambio lo que es, una vez que ha recibido la forma de ser, existe y es sustancia.

III. Lo que es puede participar de algo, pero el ser de ningún modo participa de algo. Pues hay participación cuando algo ya existe; y algo existe porque ha recibido el ser.

26 Versión según traducción Antonio Tursi, "Boecio: los axiomas del De hebdomadibus", Avatares Filosóficos, 3 (2016), 118-129, en especial 119-120. La traducción ha sido modificada en algunos de sus elementos, en concreto los relativos a las expresiones id quod est y quod est. 
IV. Id quod est, habere aliquid, praeterquam quod ipsum est, potest; ipsum vero esse nihil aliud praeter se habet admixtum.

V. Diversum est tantum esse aliquid et esse aliquid in eo quod est; illic enim accidens, hic substantia significatur

VI. Omne quod est, participat eo quod est esse, ut sit; alio vero participat, ut aliquid sit. Ac per hoc, id quod est, participat eo quod est esse, ut sit; est vero, ut participet alio quolibet

VII. Omne simplex esse suum et id quod est unum habet.

VIII. Omni composito aliud est esse, aliud ipsum est
IV. Lo que es puede tener algo más allá de lo que él mismo es, pero el ser, nada tiene añadido más allá de sí mismo.

V. Son diversos ser meramente algo y ser algo en cuanto ente, pues en el primer caso se significa accidente y en el segundo sustancia.

VI. Todo ente participa del ser, para existir; y participa de otra cosa para ser algo. Y por eso, un ente participa del ser para existir y existe para participar de cualquier otra cosa.

VII. Todo lo simple tiene su ser y el ente como algo único.

VIII. En todo lo compuesto una cosa es el ser y otra esto mismo que es.

Ocho axiomas que, en origen, recuerdan la idea aristotélica de las Categorías de buscar el significado en las concepciones comunes (usos del lenguaje), bien que en este caso lo limita a quienes conocen el tema. En el caso de Boecio, el esse y ens se consideran dos realidades distintas, identificándose la primera en Dios, y que establecen una relación de participación por medio de una forma essendi. Una imagen que, de hecho, sería transmitida a la filosofía posterior como si se tratase de una división natural de la ontología: el ser y el ente aparecen en la forma de verbos sustantivizados, como dos objetos diferentes que mantienen una relación entre sí, siendo la metafísica el estudio del ser.

\section{TIEMPOS DE CONFUSIÓN}

En esta historia de la metafísica no deben tomarse en consideración tan sólo elementos conceptuales, pues en gran medida las cuestiones modernas tienen su origen, como se ha dicho ya, precisamente en este olvido. En realidad, en este proceso tuvo una importancia considerable la situación confusa que se produjo durante la Plenitud de la Edad Media. En esta época, máxime entre finales del siglo XII y durante el XIII, el aristotelismo fue objeto de intensas discusiones en las que se implicaron tanto los autores de la época como las instituciones vinculadas a la educación ${ }^{27}$. Sin voluntad ahora de hacer una historia exacta del aristotelismo, es necesario señalar algunos hechos. El primero es que a lo largo de esta época coinciden dos fuentes de textos sobre los que se realizan las

27 En lo relativo a la evolución de la institución, vid. Bordoy, Enseñar, 19-103. 
traducciones: una es la procedente del árabe, de la que traductores como los de Toledo extraen tanto las obras auténticas de Aristóteles (caso de la Metafisica), como una serie de libros espurios (como el Liber de causis), comentarios a estos textos (caso de los compuestos por Averroes) y paráfrasis realizadas a partir de ellos (como las de Avicena); otra es la procedente del griego ${ }^{28}$, de la que se extraerán obras auténticas del Estagirita (como la Retórica o la Política) y una serie de tratados y comentarios de otros autores (caso de los Elementos de Teología de Proclo). La tradición árabe será la más importante durante el siglo XII, mientras que a finales del XIII ya predominarán las traducciones del griego, con un espacio intermedio en el que se producen a partir de ambas fuentes ${ }^{29}$. Esta situación generó un clima difícil, en el que no sólo se trataba de asimilar el pensamiento aristotélico auténtico, sino también de distinguirlo de los comentarios, paráfrasis y espurios junto a los que se había transmitido y que ya formaban parte de los textos usados por los latinos.

El segundo hecho a tener en cuenta es que el aristotelismo fue en realidad mucho más que una corriente o tradición intelectual. El siglo XIII trajo consigo el reconocimiento de los derechos de una nueva institución, la Universidad, que se convirtió en el centro por excelencia de producción intelectual y en el núcleo de la Escolástica. Las discusiones por definir los límites de esa nueva institución, la necesidad de demarcar las ciencias y, sobre todo, el deseo por parte de muchos maestros de crear un espacio propio para la filosofía, condujeron a una mayor demanda de autonomía. Por diversas cuestiones, esa demanda de autonomía fue de la mano de la vindicación del estudio y la enseñanza de las obras de Aristóteles, y de la posibilidad de discutir no sólo los textos aceptados, sino también obras como el De anima o la propia Metafísica. Esta situación condujo a exagerar la importancia del pensamiento aristotélico como foco o centro de las discusiones, generando en torno a él creencias y percepciones que, en muchos casos, se entremezclaban con ideas preconcebidas derivadas de los escritos de Averroes. Un caso claro de ello es lo que sucedió con el denominado 'averroísmo latino', tradición que para muchos fue determinante, para otros en realidad nunca tuvo el cuerpo que se le otorgó ${ }^{30}$.

28 Vid. n. 14 del presente estudio.

29 Las traducciones de Miguel Escoto, por ejemplo, se enmarcan en este contexto: a pesar de que ya se conoce la existencia de las versiones griegas e, inclusive, algunas de ellas han llegado a París y están siendo traducidas, el autor aborda la traducción desde el árabe. De hecho, incluso el propio Tomás de Aquino seguirá consultando las traducciones del árabe para elaborar su comentario a la $\mathrm{Me}$ tafísica, si bien se basará en su mayor parte en los trabajos de Guillermo de Moerbeke.

30 En torno a este tema, vid. Ana María C. Minecan, "Introducción al debate historiográfico en torno a la noción de "averroísmo latino", Anales del seminario de historia de la filosofía 27 (2010): 
En lo que a la Metafísica refiere, ambos procesos, en especial el primero, afectaron de manera ostensible. De hecho, es imposible hablar de una recepción unificada de la obra, que más bien pasa a formar parte del mundo latino de una manare gradual y progresiva. La primera versión, denominada vetustissima, fue traducida del árabe por Jaime de Venecia entre los años 1225 y 1250, pero contenía tan sólo los libros I a IV ${ }^{31}$, es decir, desde la historia de la filosofía y el concepto de sabiduría hasta la definición de la ontología. De esta primera versión aparecerá un texto revisado entre los años 1220 y 1230, de autor anónimo, conocida como vetus y que contiene los mismos libros que la vetustissima. La segunda versión conocida, denominada media, hizo su aparición a mediados del siglo XII, después de la de Jaime de Venecia, se desconoce su autor, si bien se sabe que carece del libro XI. Entre los años 1220 y 1235, pese a disponer ya de textos de origen griego, aparece la traducción de Miguel Escoto, denominada nova, también parcial, pues incluye los libros I (cap. 5 a 10), II, III a X y XII (capítulos 2 a 10). La versión más moderna, la novae translationis, está hecha ya directamente a partir del griego por Guillermo de Moerbecke. No se puede considerar que esta última versión, aparecida antes del año 1272, se convirtiese en la dominante, pues la elaboración de comentarios, en casos como el de Tomás de Aquino, siguió comparando versiones procedentes de ambas lenguas e incluso analizando los originales.

Las imágenes actuales de lo que sucedió en este período tienden a generar una unidad excesiva sobre todo el proceso: las versiones del árabe y su consiguiente mezcla con tratados que no eran de Aristóteles; las traducciones a partir del griego, que generan ya un conocimiento exhaustivo; $y$, en fin, los comentarios definitivos que parten de estos últimos trabajos. El proceso es, en cambio, complejo y superpuesto. El caso del Liber de causis, uno de los tratados que llegaron con las traducciones a partir del árabe, resulta un buen ejemplo: el propio Alberto Magno es consciente de que no es un tratado original de Aristóteles, mucho antes de que Tomás de Aquino pudiese observar que se trataba de una paráfrasis parcial de los Elementos de teología de Proclo; no fue, por consiguiente, el descubrimiento de su autenticidad lo que determinó que fuese abordado como parte del conocimiento aristotélico. De este modo, durante más de un siglo se fueron mezclando conceptos procedentes de las diferentes tradiciones y el peso de obras como la Isagoge de Porfirio, en la versión latina de Boecio, se erigieron como la forma de interpretar la distinción entre el esse y el ens.

63-85 y Pilar Herráiz Oliva, "Nuevas consideraciones en torno a la noción de averroísmo", Enrahonar: an international journal of theoretical and practical reason 1 extra (2018): 35-44.

31 En este punto se utilizan las designaciones de los libros según la numeración latina, ya que es a la que se refiere. 


\subsection{Consecuencias del modelo}

Podría parecer que esta diferenciación entre el ser y la entidad unida a una estructura en la que la participación se produce mediante la forma es, pese a todo, semejante a la planteada por la Metafísica. No obstante, si se toman en consideración las obras junto a las que se transmitió el De hebdomadibus es posible ver que, en realidad, lo que parece una mera sustantivización de un verbo confiere al resultado una estructura mucho más adaptable al cristianismo. En efecto, puede verse, por ejemplo, al compararse con el Comentario al Timeo de Platón de Calcidio, quien plantea el mismo problema pero desde la perspectiva de las Formas: sugiere Calcidio que es impensable pensar que los arquetipos que se hallan en la mente de Dios se mezclan con la materia, aunque sea por el tipo de participación que describe el Timeo; para ello, el autor del Comentario plantea la existencia de dos tipos de arquetipos, los Arquetipos que se encuentran en la mente de Dios, y los arquetipos que son el resultado de su plasmación fuera de él -es decir, sobre lo que no es-, de tal modo que aquello que se mezcla con la materia no está en Él, sino que es un resultado, una copia, de las formas que en él se encontraban. Mediante la postulación de una forma essendi, Boecio salva un problema equiparable que podría conducir a un panteísmo para estructurar que la participación con las entidades no implica dependencia o contacto con éstas por parte de Dios.

Llegado este punto, es posible ver cómo en el siglo XIII la distinción boeciana está asentada y que se transmite sobre la propia interpretación de Aristóteles. Comparemos por un momento la versión griega y la traducción de Guillermo de Moerbecke que, a juicio general, es la más cercana al original ${ }^{32}$ :

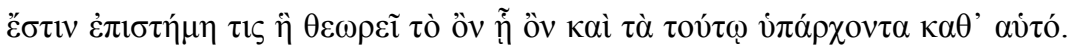

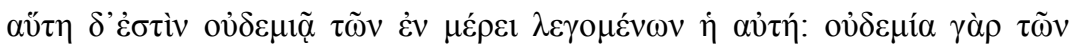

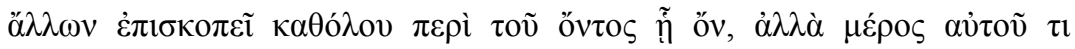

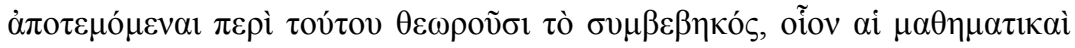
$\tau \tilde{\omega} v \dot{\varepsilon} \pi ı \tau \tau \mu \tilde{\omega} v$.

Hay una ciencia que estudia lo que es, en tanto que algo que es, y los atributos que, por sí mismo, le pertenecen. Esta ciencia, por lo demás, no se identifica con ninguna de las denominadas ciencias particulares. Ninguna de las otras [ciencias], en efecto, se ocupa universalmente de lo que es, en tanto que algo

32 Ar. Met. 1003a21-26. La traducción del texto griego está tomada de la versión de T. Calvo, Aristóteles. Metafisica, Madrid: Gredos, 1994, que, a nuestro juicio, es la que, en lengua castellana, se ajusta mejor al sentido del original. El texto latino y su traducción han sido tomados de Valentín García Yebra, Metafisica de Aristóteles. Edición trilingüe (Madrid: Gredos, 2012). La versión latina utilizada por este autor corresponde a la traducción de la Metafísica de Guillermo de Moerbecke. 
que es, sino que tras seccionar de ello una parte, estudia los accidentes de ésta: así, por ejemplo, las ciencias matemáticas.

Est scientia quaedam quae speculatur ens in quantum est ens et quae huic insunt secundum se. Haec autem nulli in parte dictarum eadem; aliarum enim nulla intendit universaliter de ente in quantum est ens. Verum partem eius abscindentes aliquam circa hanc speculantur accidens, velut scientiarum mathematice.

Hay una ciencia que contempla el Ente en cuanto ente y lo que le corresponde de suyo. $\mathrm{Y}$ esta ciencia no se identifica con ninguna de las que llamamos particulares, pues ninguna de las otras especula en general acerca del Ente en cuanto ente, sino que, habiendo separado alguna parte de él, consideran los accidentes de ésta; por ejemplo, las ciencias matemáticas.

Dos son los grandes cambios que se han producido en la traducción de Guillermo de Moerbecke. En la versión griega, la acción que se asocia a la ciencia buscada es descrita con el verbo $\theta \varepsilon \omega \rho \varepsilon ́ \omega$, mientras que en la latina se define como speculatur. En la época en la que es compuesta la Metafísica, $\theta \varepsilon \omega \rho \varepsilon ́ \omega$ se define como una acción relacionada con el entendimiento susceptible de ser traducida como contemplar o considerar. Esta acción tiene, no obstante, un referente directo, pues el verbo se utiliza asimismo como la acción de observar un espectáculo - tal y como describe Pitágoras según Cicerón- o como revisión o mirada sobre algo. En gran medida, el uso verbal de Aristóteles está destinado a una observación directa, lejos de la idea de una abstracción como podría pensarse en la actualidad: se trata de una ciencia que mira a su objeto. El verbo latino speculare traduce, en principio, el griego $\theta \varepsilon \omega \rho \varepsilon ́ \omega$, pero en la forma que ha adquirido en el ámbito intelectual de los siglos XI-XIV, tiene un sentido distinto: se trata de una acción del pensamiento de observar, pero ésta está orientada a la visión de la verdad, sin relación directa con el mundo natural. De hecho, el concepto de especulación está vinculado, desde la división de las ciencias de Casiodoro, a la abstracción, definiéndose como un proceso que conduce a la elevación del entendimiento. La diferencia puede parecer nimia, pero con la traducción se pierde el concepto de una mirada directa a lo que se encuentra frente al sujeto, algo que se muestra en los otros elementos que distinguen la traducción de Guillermo de Moerbecke del texto de Aristóteles.

La diferencia más importante entre ambas versiones reside en el objeto de la ciencia primera en tanto que universal. Si en la versión griega figura la expresión $\tau o ̀$ òv ens in quantum est ens, a saber, el ente en tanto que es ente. Ya se ha analizado el significado lingüístico de la versión griega, que cabe recordar hacía referencia 
a un participio que indicaba movimiento. El ens, en cambio, refiere a un sujeto que corresponde a un sustantivo, eliminando, al menos en la expresión lingüística, la idea de movimiento. Es cierto que, en autores como Tomás de Aquino, el ente se plantea como aquello primero y más conocido, lo que el entendimiento ve y percibe en primer lugar ${ }^{33}$. Sin embargo, incluso en esta versión se elimina el carácter general que le otorga Aristóteles, reduciéndolo a un objeto identificable en sí: la traducción de Moerbecke supone el paso de una forma indeterminada verbal, de la idea que la ciencia analiza lo que se encuentra existiendo, a la concepción de cosas que existen, sin presuponer, como hace el Estagirita, que dicha característica ser se encuentra ya en ellas mismas.

\section{EL EFECTO DE LA CONFUSIÓN: LAS DIVISIONES DE LAS CIENCIAS}

Uno de los aspectos de la cultura medieval en el que mejor se evidenciaron las diferencias entre una tradición latina heredera del pensamiento Boecio y una filosofía árabe que se había constituido en gran medida gracias a Aristóteles, es en las sucesivas demarcaciones de las ciencias que, desde el siglo XII, compiten por estructurar el conocimiento. Resulta sencillo observarlo a partir de la comparación de dos propuestas de estructura: la que aparece en el Didascalion de Hugo de San Víctor; y la que se deriva del De divisione philosophiae de Domingo Gundisalvo. En el primer caso, el Didascalion presenta un esquema de fondo asentado sobre tres elementos: los dos Fundamentos y los comentarios de Boecio a las obras de Aristóteles; la estructura categorial de Porfirio de Tiro, tal y como es transmitida en la versión latina de la Isagoge; y las Etimologías de Isodoro de Sevilla, que fundamentaron el conocimiento latino durante siglos. En términos generales, Hugo de San Víctor toma de estos autores las bases para erigir los objetos y alcance de las partes que conforman la filosofía, que a su vez es entendida como disciplina, arte de las artes o método para poder pensar la muerte. La estructura que les confiere el Didascalion puede ser plasmada del siguiente modo ${ }^{34}$ :

33 Tomás de Aquino, De ver. Q. 1, a. 1.

34 Hugo de San Víctor, Didasc. II.1. 


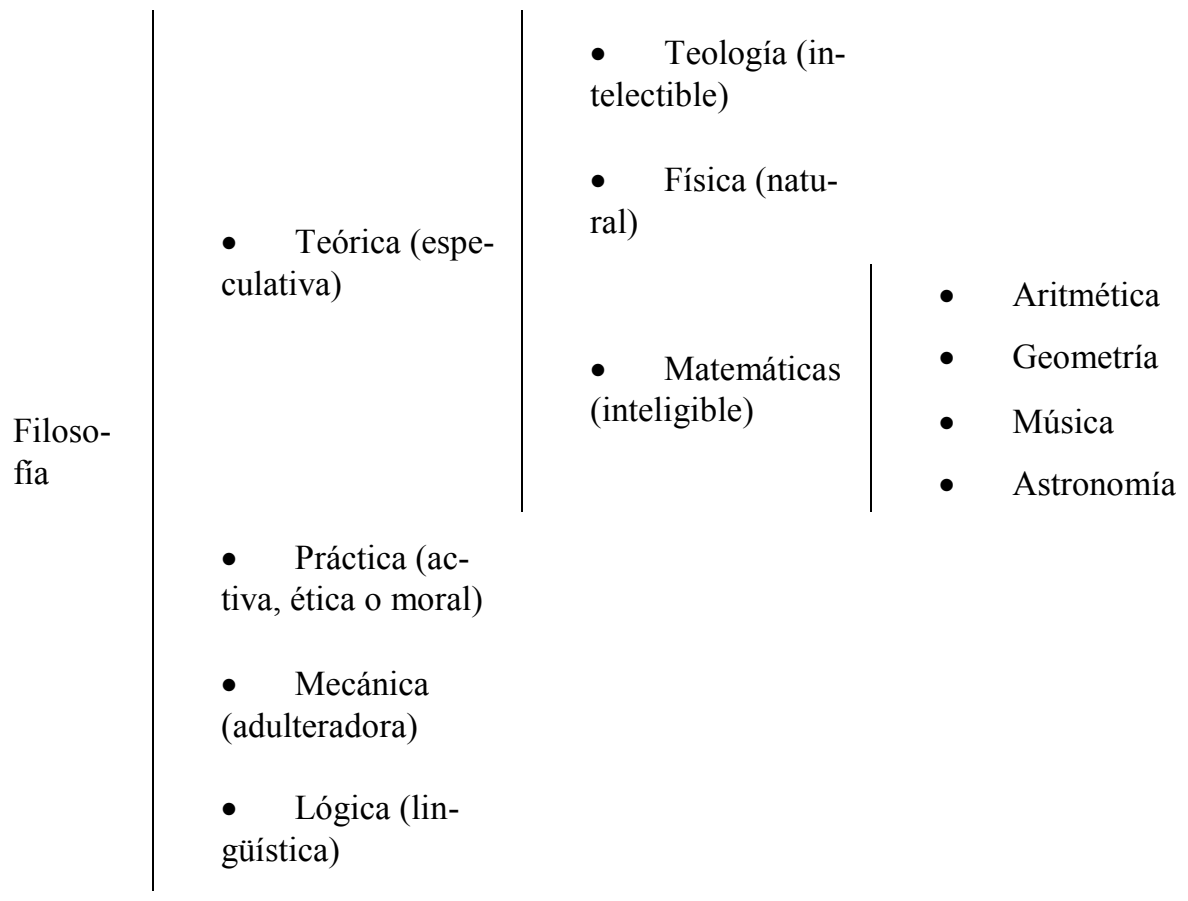

En este esquema, es posible observar que la parte de la filosofía que más se aproxima a la versión aristotélica la constituye la teórica, a la cual le corresponde el acto de especular. No resulta difícil, en este sentido, ver que en ella ya están contenidos los elementos básicos que generarán, más adelante, la traducción de tò òv como ens en la versión de -Guillermo de Moerbecke. Dicha especulación se basa en la abstracción que, a su vez, se deriva en la teología, que analiza lo intelectible, la filosofía natural y las matemáticas. El estudio de la sustancialidad aparece enmarcado, en este contexto, como una parte de un esquema general que no aborda las entidades en sí, pues las matemáticas, que representan un estado inferior, han producido ya una primera abstracción, que es sobre la que opera la filosofía natural o física.

El modelo de estructuración de las ciencias cambia de forma sustancial si se compara con la división de las ciencias que aparece en el De divisione philosophiae de Domingo Gundisalvo. Éste, a diferencia de Hugo de San Víctor, no construye su esquema a partir de la tradición latina, sino que se encuentra influenciado por las traducciones árabes, en especial la de la Shifấ' de Avicena ${ }^{35}$. Algunos autores han sugerido que el esquema resultante combina aún elementos

35 Vid. Alexander Fidora, "Domingo Gundisalvo y la introducción de la 'metafísica' al occidente latino", Disputatio. Philosophical Research Bulletin, 3.4 (2014): 51-70. 
que proceden del mismo Boecio e, inclusive, de la Escuela de Chartres ${ }^{36}$, pero que el núcleo doctrinal presenta una fuerte influencia tanto del mencionado Avicena como de las doctrinas de al-Fârâbî. El modelo resultante es distinto ${ }^{37}$ :

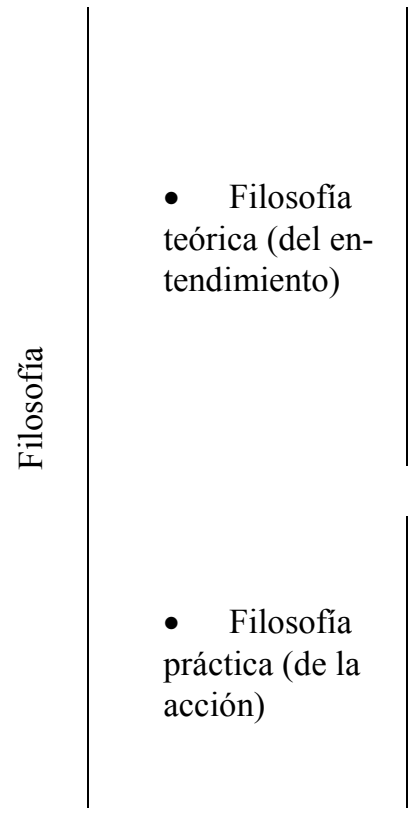

- Teología, ciencia primera, filosofía primera o metafísica

- Matemática o ciencia disciplinaria

- Aritmética - Geometría - Música - Astronomía

- Física o ciencia natural

- Ciencia de la disposición de la conversación con los demás seres humanos - Ciencia de la disposición de la casa y de la familia - Ciencia de la ordenación individual del hombre

La filosofía no corresponde ya únicamente a la especulación, sino que conserva la raíz del verbo $\theta \varepsilon \omega \rho \varepsilon ́ \omega$ para erigirse en 'filosofía teórica' o del entendimiento. Asimismo, las matemáticas no constituyen ya el punto de relación primero con las entidades, sino que a éstas les precede la física o ciencia natural. No obstante, el elemento que más evidencia las diferencias entre ambos autores es que Gundisalvo deja de considerar la filosofía como una 'disciplina' para convertirla en 'ciencia', recuperando de este modo la imagen de Aristóteles.

En la segunda mitad del siglo XIII, cuando Guillermo de Moerbecke realiza su traducción de la Metafísica, ambos modelos, el procedente de la tradición latina cristiana y el generado a partir de la influencia árabe, han tenido ya un largo recorrido de confrontación y síntesis. No es de extrañar, por consiguiente, que cuando Tomás de Aquino compone su comentario al capítulo 1 del libro IV pueda afirmar, sin necesidad de justificarlo, que Aristóteles "supponit aliquam esse scientiam cuius subiectum sit ens". Una afirmación en la que, de un lado, se observa el progreso de haber logrado recuperar un ámbito de la metafísica

36 Cf. Fidora "Domingo Gundisalvo," p. 56

37 Se sintetiza aquí la estructura que aparece en De divisione, 12-18. 
para la filosofia, pero que, de otro lado, mantiene una imagen ya consolidada de la entidad que permite distinguirla del ser, es decir, como afirma Boecio en el axioma VIII, "omni composito aliud est esse, aliud ipsum est".

\section{UNA METAFÍSICA CON O SIN HISTORIA DE LA METAFÍSICA}

La historia es una ciencia de la que podría decirse, siguiendo la división aristotélica, es deseada de dos formas distintas: de un lado, constituye un fin en sí misma, es una disciplina autónoma cuyos resultados se expresan a modo de conocimiento de nuestro pasado; de otro lado, no obstante, es también deseada como una parte indispensable del resto de las ciencias, a las que ofrece el conocimiento de su pasado, de sus contenidos. Un doble valor que, pese a todo, no supone que también deban ser múltiples sus metodologías, de tal manera que unos sean los principios que se apliquen en el seno de esta disciplina y otros los que se utilicen cuando cada una de las ramas del saber particulares estudia su pasado. Esta necesidad no se refiere a las especificidades que, es evidente, plantean los objetos de estudio de cada una de las ciencias. Se trata de utilizar un método histórico que no se rija por los parámetros internos de la ciencia que lo utiliza, sino por los mismos principios a los que recurre la historiografía moderna. Sólo de este modo es posible lograrse definir una imagen no distorsionada de una ciencia, en la que la realidad del presente no condicione el desarrollo de un pasado, sin concebir el tiempo como una evolución acumulativa.

En el caso de la metafísica, el olvido en cierta época de esta necesaria relación con la historia, unido a la aparición de autores que se convirtieron en referentes, condujo a dibujar un pasado concreto cuya imagen perdura incluso en la actualidad. Las tendencias dominantes en Occidente quisieron ver en la Grecia clásica el origen de lo que eran en los siglos XIX y XX, creando con ello un mito de origen: la Edad Media se convirtió en el personaje malvado que encerraba la filosofía en el cristianismo dándole forma de filosofemas; Grecia fue, en cambio, un héroe, que se mitificó unificando a todos los griegos bajo el concepto de unos 'Griegos' que, en palabras de G. Most, eran en realidad alemanes ataviados con togas. Todo ello no resultaría grave si tan sólo se tratase de una imagen, pero al trasladarse esta visión sobre la filosofía griega se desdibujaron los conceptos básicos que en la época articulaban la metafísica y, en especial, la ontología: de manera sutil pero efectiva, la concepción griega de lo que es se transformó en entidad, abriendo el paso a la separación entre ésta, el ser, la esencia y la existencia. En su origen, una falta de método histórico que llevó al olvido de que nuestros conceptos no procedían de Aristóteles, sino más bien de un 
patricio que llegó a lo más alto de la sociedad romana, para después caer en desgracia y tener que buscar el consuelo de la filosofía.

\section{REFERENCIAS BIBLIOGRÁFICAS}

Aubenque, Pierre. "Aristoteles und das Problem der Metaphysik". Zeitschrift für philosophische Forschung XV/3 (1961): 117-129.

- Le problème de l'être chez Aristote. Essai sur la próblematique aristotélicienne. París: Presses Universitaires de France, 1962.

Azcárate, Patricio. Aristóteles. Metafisica. Madrid: Medina y Navarro, 1875.

Bordoy, Antoni. Enseñar filosofía en los albores de la Universidad (1200-1240). Estudio histórico acompañado del 'Acceso de los filósofos a las siete artes liberales'. Madrid, Sindéresis, 2019.

Bueno, Gustavo y Luis Martínez. Nociones de filosofía. Quinto curso. Salamanca Anaya, 1955.

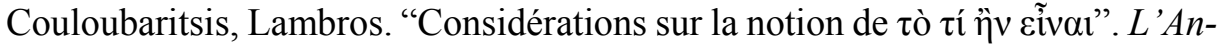
tiquité Classique 50 (1981): 148-157.

Dod, Bernardus G. "Aristoteles latinus". En Cambridge History of Later Philosophy, editado por Norman Kretzmann, Anthony Kenny y Jan Pinborg, 45-79. Cambridge, Cambridge University Press, 1982.

Fidora, Alexander. "Domingo Gundisalvo y la introducción de la 'metafísica' al occidente latino". Disputatio. Philosophical Research Bulletin, 3.4 (2014): 51-70.

Francisco, Héctor Ricardo. "La transmisión de saber aristotélico en el Cercano Oriente cristiano". El arco y la lira. Tensiones y debates 4 (2016): 85-100.

García Yebra, Valentín. Metafísica de Aristóteles. Edición trilingüe. Madrid: Gredos, 2012.

Hayling, Annie. "El problema del ser". Revista Estudios 6 (1985): 179-189.

Jaeger, Werner. Grundlegung einer Geschichte seiner Entwicklung. Berlín: Weidmann, 1923.

Lázaro, Manuel, ed. Historia de la Filosofia Medieval y Renacentista I. Madrid: UNED-Sindéresis, 2018.

León, Francisco. "Translatio Studiorum: Traslado de libros y diálogo de civilizaciones en la Edad Media". Revista General de Información y Documentación 15.2 (2006): 51-77.

Marten, Rainer. "Heidegger and the Greeks". En The Heidegger case: on philosophy and politics, editado por Tom Rockmore, 167-187. Filadelfia: Temple University Press, 1992. 
Mesquita, António Pedro. "Platón y Aristóteles. Dos ontologías en confrontación”. Estudios de Filosofia 53 (2016): 55-79.

Minecan, Ana María C. "Introducción al debate historiográfico en torno a la noción de 'averroísmo latino"'. Anales del seminario de historia de la filosofia 27 (2010): 63-85.

Most, Glenn. "Ross". Arion: A Journal of Humanities and the Classics 10 (2002): 83-89.

Oliva, Herráiz. "Nuevas consideraciones en torno a la noción de averroísmo". Enrahonar: an international journal of theoretical and practical reason 1 extra (2018): 35-44.

Ross, David. Aristotle. Londres: Methuen, 1923.

Van Steenberghen, Ferdinand. Introduction à l'étude de la philosophie médiévale. Lovaina, París: Publications Universitaires, Béatrice-Nauwelaerts, 1974.

Tarrío, José Manuel. Filosofía. $1^{\circ}$ Bachillerato. Madrid: Editex, 2019.

Tursi, Antonio. "Boecio: los axiomas del De hebdomadibus". Avatares Filosóficos, 3 (2016), 118-129.

Antoni Bordoy Fernández Departament de Filosofia i Treball Social Universitat de les Illes Balears Crta. de Valldemossa, km. 7.5 07190 Palma -Illes Balears (España) https://orcid.org/ 0000-0003-2421-6343 
